Article

\title{
Geographical Aspects of Recent Trends in Drug-Related Deaths, with a Focus on Intra-National Contextual Variation
}

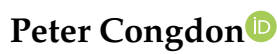

School of Geography, Queen Mary University of London, Mile End Rd, Bethnal Green, London E1 4NS, UK; p.congdon@qmul.ac.uk

Received: 14 October 2020; Accepted: 30 October 2020; Published: 2 November 2020

\begin{abstract}
Background. Recent worldwide estimates are of 53 million users of opioids annually, and of 585,000 drug-related deaths, of which two thirds are due to opioids. There are considerable international differences in levels of drug death rates and substance abuse. However, there are also considerable variations within countries in drug misuse, overdose rates, and in drug death rates particularly. Wide intra-national variations characterize countries where drug deaths have risen fastest in recent years, such as the US and UK. Drug deaths are an outcome of drug misuse, which can ideally be studied at a relatively low spatial scale (e.g., US counties). The research literature suggests that small area variations in drug deaths to a considerable degree reflect contextual (place-related) factors as well as individual risk factors. Methods. We consider the role of area social status, social cohesion, segregation, urbanicity, and drug supply in an ecological regression analysis of county differences in drug deaths in the US during 2015-2017. Results. The analysis of US small area data highlights a range of factors which are statistically significant in explaining differences in drug deaths, but with no risk factor having a predominant role. Comparisons with other countries where small area drug mortality data have been analyzed show differences between countries in the impact of different contextual factors, but some common themes. Conclusions. Intra-national differences in drug-related deaths are considerable, but there are significant research gaps in the evidence base for small area analysis of such deaths.
\end{abstract}

Keywords: mortality; contextual; opioid; drug dependence; small area

\section{Introduction}

The United Nations Office on Drugs and Crime (UNODC) estimates that there are 53 million users of opioids annually and that 585,000 people die annually worldwide (as a contributory or direct cause) due to drug misuse [1]. Two thirds of these deaths are related to opioids. Drug deaths are a major component of the disease burden associated with drug misuse [2] and, due to their disproportionate contribution to premature deaths, have been linked to the deceleration or reversal of improvement in life expectancies [3].

There are considerable international differences in drug misuse prevalence, drug use patterns, and drug-related death rates. For example, the recent upturn in drug deaths in the US and Canada has been linked to growing use of fentanyl, a synthetic opioid with potentially lethal effects at low doses [4]. By contrast, in parts of Asia and Africa, growth of drug dependence has been linked to tramadol, a less lethal opioid ([5], pp. 23-26).

Variations in drug-related deaths within countries are also pronounced and generally less well documented. Research into reasons for such variations is also relatively limited. Where data are available, they show wide disparities. For example, drug overdose mortality rates in US states (2017 data) 
vary 7-fold, from 8.1 per 100 thousand in Nebraska to 57.8 per 100 thousand in West Virginia [6]. In Scotland, drug death rates (for 2014-2018) by local authority range from 5 per 100,000 (Orkneys) to 31 per 100,000 (Dundee) [7].

As discussed in the literature on risk environments [8,9], such wide contrasts are difficult to explain solely in terms of the individual risk factor pattern of different area populations (also known as compositional factors), and contextual factors (place effects, due, for example, to structural economic shifts) are relevant also $[10,11]$.

In some ways, the contextual-compositional distinction may be reductionist, and recognition of broader influences on individual behaviours is needed [12,13]. For example, under a relational perspective, context and composition are not mutually exclusive since the health status of places results from interactions of people with the wider environment. Bambra et al. [13] argue for a political economy approach which recognizes the role of structural drivers of geographic health inequalities. For example, in the case of drug-related mortality in the US, these might include variations between US states in drug law enforcement, drug addiction treatment, and naloxone accessibility [14].

Below, we discuss in more detail the main themes in the research literature on small area variations in drug-related deaths and summarize the findings of the ecological (area-based) studies on the factors associated with such variation. As an illustrative example of the issues involved, we then consider variation in drug deaths between 3141 US counties during the period 2015-2017. We use a Bayesian regression method [15], and find the relative risk of drug deaths to be especially associated with area income contrasts and social capital, with lesser impacts of ethnic segregation, unemployment, urbanicity, and drug supply. We also find evidence of considerable spatial clustering in drug deaths.

\section{Factors Underlying Intra-National Variation in Drug-Related Deaths}

Interlinked themes are present in the literature on contextual variations in drug-related deaths within countries. Among recurring themes is the notion of "deaths of despair", combining drug and alcohol-related deaths and suicide. This concept has been applied particularly to the United States [16,17] but has relevance for other high-income countries with high increases in drug deaths, including parts of the UK [18].

A predominant theme in the literature relating to deaths of despair is the effects of job losses (especially male jobs) due to de-industrialization and associated reductions in community cohesion and economic opportunity, for example, in US rust belt areas. Hence, it may be expected that unemployment contrasts between small areas, or changes in unemployment, would be associated with drug-related deaths [19]. The impact of economic restructuring is arguably especially on white males, and may partly explain the male excess in drug deaths as well as adverse trends in mortality [20]. Thus, as summarized in [21], "less-educated white males suffer overdose deaths at such a high rate that it has lowered their overall life expectancy".

However, there have been skeptical studies regarding the central role of de-industrialization [22], and other aspects of employment change, such as job losses related to international trade, have been proposed as a source of geographic variation in US drug deaths [21].

Alternative, more broadly based socio-economic factors have been proposed, such as material deprivation and income segregation. Thus, Boardman et al. [23] find neighborhood poverty acting to raise drug misuse, even after individual risk factors are controlled for, while Monnat [24] considers a range of indices of distress and forms of labor market dependence as potential sources of varying drug death rates in US counties over 2006-2015.

As to UK evidence, a study of drug deaths in England and Wales [25] found a "steep socio-economic gradient" in drug deaths, while an official review [26] of drug deaths in Scotland argues that "the single biggest structural driver of problem drug use is poverty and deprivation", later amplifying that "it is not necessarily the case that poverty in itself is a direct driver of problematic drug use; however, those in poverty are more likely to be exposed to additional risk factors, such as unstable 
home life, unemployment, and adverse childhood experiences which increase the likelihood of a person being predisposed towards problematic substance use".

The social environment, as measured by social capital and social cohesion, may affect associations between neighborhood-level poverty and drug misuse rates $[27,28]$. In particular, social cohesion may act as a protective factor that moderates the impact of poverty [29], with lower misuse and mortality in deprived areas that are relatively cohesive, but higher misuse and mortality where deprivation is reinforced by low cohesion. Thus, Aslund and Nillson [30] report in a Swedish study of adolescent substance use that "subjects within the group with low neighborhood social capital had ... more than double the odds of having used illicit drugs compared with individuals with high neighborhood social capital". Regarding US states, we find a correlation of -0.34 between age adjusted drug-related death rates over 2015-2017 and state level averages of social capital, extracted from https://aese.psu.edu/nercrd/community/social-capital-resources [31]. However, not all studies report a significant impact of social capital on drug misuse and overdose, with Gatti et al. [32] finding that drug overdose rates in Italian provinces were mostly determined by area socio-economic status.

Poverty effects may also be amplified by racial segregation, as mostly US studies (e.g., [33,34]) show. Segregation may impact on mental health, with Cooper et al. [33] mentioning that "black residents of segregated communities are at elevated risk of depression, anxiety, and general psychological distress". Effects of segregation may extend beyond ethnic segregation to include measures of social segregation more generally, such as poverty segregation [34] and income inequality [35].

The urban status of small areas may also be relevant to drug-related deaths. The broader literature on drug deaths suggests that drug-related mortality may be lower in rural areas, especially after area socio-economic status is allowed for (e.g., in the USA, this would be after allowing for the impact of lower rural incomes). Urban physical environments may affect levels of drug abuse and drug deaths [36,37], e.g., by facilitating access to drugs. With regard to the US, Hedegaard et al. [38] report that "the age-adjusted rate of drug overdose deaths was higher in urban than in rural counties (22.0 and 20.0 per 100,000, respectively)".

Supply side factors may also influence drug death levels, with higher mortality associated with easier access. For example, Monnat [39] investigates opioid supply factors (exposure to prescription opioids and fentanyl supply) as influences on US county drug mortality over 2014-2016. In the US, increases in opioid supply, through over-prescribing or illegal access, have been cited as a factor explaining increased opioid-related mortality, as opposed to job losses and "deaths of despair". Ruhm [40] investigates "the alternative hypothesis that changes in the drug [supply] environment are a main cause of rising overdose deaths". He finds a significant impact of opioid prescribing patterns on drug deaths at US county level, after adjusting for incomplete reporting of drug involvement on death certificates. Relevant also to the influence of supply factors in the US is a demarcation of phases of the opioid crisis. Thus, DeWeerdt [41] argues that "The opioid epidemic has had three phases: the first was dominated by prescription opioids, the second by heroin, and the third by cheaper-but more potent-synthetic opioids such as fentanyl. All of these forms of opioid remain relevant to the current crisis". Excess prescribing of opioids has also occurred in the UK [42] and Canada [43].

\section{Data and Methods}

The US has had one of the world's fastest growth rates in drug-related deaths generally and opioid-related deaths in particular. Drug deaths involving any form of opioid-prescription opioids, other synthetic opioids (such as fentanyl), and heroin-rose from 18,515 in 2007 to 47,600 in 2017, before declining slightly to 46,802 in 2018. The majority (around $70 \%$ ) of deaths were among males. The age-standardized rate for all drug-related mortality rose from 6.1 per 100,000 in 1999 to 21.7 in 2017 [44].

We consider a regression relating drug-related deaths in US counties between 2015 and 2017 to area characteristics. Drug deaths were defined with ICD10 codes X40-X44, X60-X64, X85, and Y10-Y14 [44]. We apply a regression methodology appropriate to the form of the outcome, namely a positive count. 
This methodology is sometimes referred to as Bayesian disease mapping [45]. Specifically, we use a Poisson regression with log link, where the log link is needed to ensure that the regression produces a positive predicted response; this method is set out in Appendix A. We also allow for the fact that small death counts are not provided for some areas (see Appendix B). The goal of disease mapping is to estimate relative risks of drug-related death for each county in the US, where the US-wide relative risk is 1 [46]. For example, an extremely high relative risk might be 5, and a low relative risk might be 0.1 or 0.2 . The model involves known variables which are postulated risk factors but also includes two sets of random effects: one set represents spatially correlated but unobserved risk factors, the other represents Poisson extra-heterogeneity (also called over-dispersion) since the variance of drug deaths exceeds the mean number of drug deaths.

We also study whether regression coefficients vary over the USA. If there were such variability, then this would be an example of geographic heterogeneity. Classical methods to investigate this include geographically weighted regression $[47,48]$, whereas the Bayesian approach, adopted here, involves spatially varying regression through use of random effects $[49,50]$.

Spatial correlation in relative risks of drug deaths is to be expected [51,52], and we can assess this from the model. Summary measures such as Moran's I can be used. We can also apply a Bayesian estimator of local indicators of spatial association (LISA) clustering [53], used by Wilt et al. [54] in connection with drug deaths. We obtain the probability that county $i$ is a high-high cluster core, namely a high mortality county surrounded by similarly high mortality counties. These probabilities can also be obtained for low-low clusters, where a low mortality county is surrounded by similarly low mortality counties.

There are seven variables, $X_{1}$ to $X_{7}$, postulated as risk factors for drug deaths. We consider two alternative specifications for $X_{1}$, the variable used to measure employment opportunities. The first specification uses the 2016 county unemployment rate, while the second uses the percent point difference between unemployment in 2016 and in 2006.

$\mathrm{X}_{2}$ serves both as an indicator of area socio-economic status and a measure of within county income disparities. It is an index of concentration at extremes, abbreviated as ICE [55], obtained from the 2016 American Community Survey as $\left[(\text { t.high })_{i}-(\text { t.low })_{i}\right] / T_{i}$, where $T_{i}$ is total households in county $\mathrm{i}$, (t.high) is the number of households with incomes over $\$ 150,000$ and (t.low) is the number of households with incomes below $\$ 15,000$. The highest and lowest scores on this index are for Loudoun (Virginia) and Holmes county (Mississippi), respectively. This variable was found to be a clearer measure of area socio-economic status in the regression than county poverty rates.

$X_{3}$ is a measure of social capital based on the index of Rupasingha et al. [31]. $X_{4}$ is a measure of urban-rural status, namely the 2010 Census proportion of county population living in rural areas. $X_{5}$ is a measure of racial-ethnic segregation from the County Health Rankings (https://www. countyhealthrankings.org/); this is an index of dissimilarity where higher values indicate greater residential segregation between non-white and white county residents.

$X_{6}$ and $X_{7}$ are measures of drug availability and supply and are at state level. $X_{6}$ is an indicator of illicit supplies of fentanyl [56] calculated using data collected under the National Forensic Laboratory Information System (NFLIS) scheme. This is calculated as a ratio of seizures to the population aged 15-64; this age group is used to correct for the impact of population size as illegal opioid use is concentrated in these ages and tails off sharply among the over $65 \mathrm{~s}$ [57]. $\mathrm{X}_{7}$ is a measure of legal opioid prescribing [58], though it should be noted that legal prescription opioid use is a risk factor for illicit drug use-for example, of heroin [59]. As noted in [58], prescribing rates for opioids vary widely, and while the overall opioid prescribing rate in 2018 was 51.4 prescriptions per 100 people, some areas have rates six times higher than that.

We use the program WINBUGS [60] (MRC Biostatistics Unit, University of Cambridge, Cambridge, UK) to carry out estimation of the model. Estimation involves two chains to 20,000 iterations, with assessment of convergence based on Brooks-Gelman-Rubin diagnostics [61]. Comparisons of fit between models are based on the WAIC (Watanabe-Akaike information criterion) [62], which is lower 
for better fitting models. This is relevant to comparing the alternative specifications for job availability, namely a model based on unemployment in 2016 and a model based on percent point differences in unemployment between 2006 and 2016.

\section{Results}

\subsection{Regression Findings}

Table 1 shows the Poisson regression coefficients of the postulated risk factors under the alternative models for employment opportunities. The respective WAIC values on the unemployment and unemployment growth models are 20,315 and 20,356, so the unemployment model (top panel in Table 1) performs best.

Table 1. Covariate effects. Coefficients and relative risks.

\begin{tabular}{|c|c|c|c|c|c|c|}
\hline $\begin{array}{l}\text { Model Version and } \\
\text { Area Predictor }\end{array}$ & $\begin{array}{l}\text { Estimated } \\
\text { Coefficient }\end{array}$ & $2.5 \%$ & $97.5 \%$ & $\begin{array}{l}\text { Relative Risk of Drug-Related } \\
\text { Mortality (Highest vs. Lowest } \\
\text { County Score) }\end{array}$ & $2.5 \%$ & $97.5 \%$ \\
\hline \multicolumn{7}{|l|}{ Unemployment Model } \\
\hline Constant & -0.12 & -0.23 & -0.03 & & & \\
\hline Unemployment & 0.33 & 0.06 & 0.59 & 1.39 & 1.07 & 1.81 \\
\hline ICE (High vs. Low Incomes) & -0.58 & -0.70 & -0.42 & 0.56 & 0.50 & 0.66 \\
\hline Social Capital & -0.57 & -0.96 & -0.21 & 0.57 & 0.38 & 0.81 \\
\hline Rurality & -0.31 & -0.40 & -0.23 & 0.73 & 0.67 & 0.79 \\
\hline Race Segregation & 0.36 & 0.26 & 0.45 & 1.43 & 1.29 & 1.57 \\
\hline Opioid Prescribing & 0.17 & 0.05 & 0.26 & 1.18 & 1.05 & 1.81 \\
\hline Fentanyl Seizure Rate & 0.19 & 0.04 & 0.37 & 1.21 & 1.04 & 1.30 \\
\hline \multicolumn{7}{|l|}{ Growth in Unemployment Model } \\
\hline Constant & -0.14 & -0.28 & -0.01 & & & \\
\hline Growth in Unemployment & 0.25 & 0.07 & 0.41 & 1.29 & 1.08 & 1.51 \\
\hline ICE (High vs. Low Incomes) & -0.71 & -0.84 & -0.59 & 0.49 & 0.43 & 0.55 \\
\hline Social Capital & -0.51 & -0.82 & -0.14 & 0.60 & 0.44 & 0.87 \\
\hline Rurality & -0.29 & -0.36 & -0.21 & 0.75 & 0.70 & 0.81 \\
\hline Race Segregation & 0.35 & 0.23 & 0.48 & 1.41 & 1.27 & 1.62 \\
\hline Opioid Prescribing & 0.16 & 0.06 & 0.25 & 1.18 & 1.07 & 1.28 \\
\hline Fentanyl Seizure Rate & 0.17 & 0.03 & 0.31 & 1.19 & 1.04 & 1.37 \\
\hline
\end{tabular}

ICE: index of concentration at extremes.

The risk factors listed in Table 1 are in a [0,1] form, with the value 1 corresponding to the maximum score, and 0 to the minimum score. Since the risk factors are on a common scale, the regression coefficients can be directly compared to assess their relative importance in explaining variation in risks of drug-related death between counties. The Poisson regression involves a log link model for relative risks of drug death. Thus, exponentiating the regression coefficients shows the relative risk of drug death when the county with the highest score on, say, social capital, is compared with the county having the lowest score. Thus, from Table 1 , counties with high social capital have around half (0.57) of the risk of drug death than those with low social capital.

The highest coefficients (in absolute terms) are for social capital and area income disparities (high vs. low income groups). High levels of social capital in a county reduce the risk of drug-related death, and the same applies to counties with high percentages of households with incomes over $\$ 150,000$ and/or low percentages of households with incomes under $\$ 15,000$. Remaining risk factors all have significant effects (in the sense that their $95 \%$ intervals are confined either to negative or to positive values) but have lesser impacts than social capital and area income contrasts.

\subsection{Spatial Clustering in Drug Death Risks}

As discussed above, we can assess the extent of spatial clustering in risks of drug-related deaths. A simple summary of spatial clustering is provided by Moran's I (e.g., [63]), obtained using the 
$\mathrm{R}$ program spdep and the moran.test option. We find a high Moran value for estimated relative risks of drug-related deaths, namely 0.72 (sd 0.01 ). This partly reflects high spatial correlation in the risk factors: social capital, unemployment, and ICE indicators have respective Moran values of $0.50(0.01), 0.63(0.01)$, and $0.61(0.01)$. Lesser correlation shows for race segregation and rurality, respectively $0.29(0.01)$ and $0.32(0.01)$.

Regarding Bayesian estimation of LISA clusters, as part of the estimation process, we can determine which counties have an over $95 \%$ probability of being high risk (i.e., a relative risk over 1) for drug-related mortality. Similarly, we can determine which areas have a more than $95 \%$ probability of being high risk cluster centers; that is, not only is the county itself a high risk area but so also is the set of counties adjacent to it. This is a "high mortality area near high mortality" in the terminology of Wilt et al. [54]. Analogously, we can determine counties which have high probabilities of being low risk and of being low mortality near low mortality.

\subsection{Skew Patterns and Spatial Concentration in Drug Death Risk}

Table 2 shows the locations of such counties according to US state. One thing to notice immediately is that whereas only 585 of 3141 counties (or 19\%) are definitively high risk, 1873 (or 60\%) are definitively low risk - that is, the geographic risk pattern is highly skewed. High risk of drug-related death is highly concentrated geographically in the United States, whereas low risk is the pattern typical of much of the USA.

High risk counties near other high risk counties account for the majority (429 out of 585) of high risk counties. There are a relatively small number of counties (125) which are spatial outliers, namely high risk themselves but surrounded by counties which are not definitively high or low risk. There is also a small number (31) of high-low counties, where a high risk county is surrounded by low risk areas.

Figure 1 shows that high risk clusters are mainly in the northeast, extending into some adjacent midwest states (Ohio) and to some southeast states (Kentucky, Tennessee, Delaware, Maryland, West Virginia) including Appalachia. The exceptions to high risk in the northeast are more rural counties in New York and Vermont. Other locations of localized high risk are in Arizona, New Mexico, and Oklahoma.

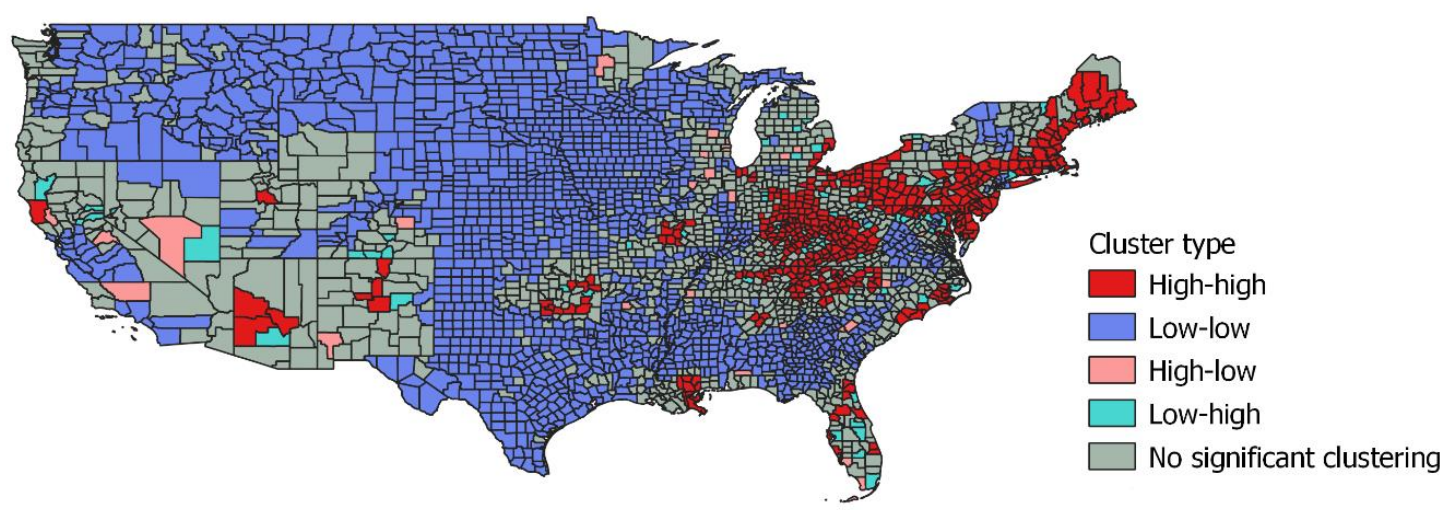

Figure 1. Continental USA. Drug-related mortality 2015-2017, cluster types. 
Table 2. Distribution of Risk and Risk Cluster Status across US States.

\begin{tabular}{|c|c|c|c|c|}
\hline \multicolumn{5}{|c|}{ Percent of Counties Which Are } \\
\hline State & High Risk & Low Risk & $\begin{array}{l}\text { High-High } \\
\text { Cluster Centers }\end{array}$ & $\begin{array}{c}\text { Low-Low } \\
\text { Cluster Centers }\end{array}$ \\
\hline Alabama & 7 & 73 & 4 & 66 \\
\hline Alaska & 0 & 86 & 0 & 82 \\
\hline Arizona & 47 & 13 & 20 & 0 \\
\hline Arkansas & 3 & 68 & 0 & 61 \\
\hline California & 12 & 60 & 2 & 38 \\
\hline Colorado & 6 & 78 & 0 & 55 \\
\hline Connecticut & 88 & 12 & 88 & 0 \\
\hline Delaware & 100 & 0 & 100 & 0 \\
\hline District of Columbia & 100 & 0 & 0 & 0 \\
\hline Florida & 27 & 34 & 15 & 18 \\
\hline Georgia & 6 & 72 & 1 & 67 \\
\hline Hawaii & 0 & 100 & 0 & 100 \\
\hline Idaho & 0 & 82 & 0 & 77 \\
\hline Illinois & 8 & 57 & 1 & 47 \\
\hline Indiana & 37 & 29 & 29 & 16 \\
\hline Iowa & 0 & 95 & 0 & 95 \\
\hline Kansas & 0 & 94 & 0 & 94 \\
\hline Kentucky & 52 & 24 & 48 & 12 \\
\hline Louisiana & 14 & 56 & 11 & 52 \\
\hline Maine & 56 & 0 & 63 & 0 \\
\hline Maryland & 88 & 12 & 83 & 4 \\
\hline Massachusetts & 71 & 7 & 71 & 0 \\
\hline Michigan & 22 & 35 & 5 & 17 \\
\hline Minnesota & 1 & 87 & 0 & 87 \\
\hline Mississippi & 4 & 84 & 2 & 79 \\
\hline Missouri & 10 & 63 & 7 & 55 \\
\hline Montana & 0 & 96 & 0 & 96 \\
\hline Nebraska & 0 & 100 & 0 & 100 \\
\hline Nevada & 24 & 59 & 0 & 12 \\
\hline New Hampshire & 80 & 0 & 80 & 0 \\
\hline New Jersey & 57 & 24 & 52 & 19 \\
\hline New Mexico & 30 & 33 & 12 & 6 \\
\hline New York & 24 & 37 & 13 & 27 \\
\hline North Carolina & 38 & 23 & 31 & 6 \\
\hline North Dakota & 0 & 100 & 0 & 100 \\
\hline Ohio & 65 & 6 & 61 & 0 \\
\hline Oklahoma & 26 & 43 & 14 & 23 \\
\hline Oregon & 0 & 78 & 0 & 69 \\
\hline Pennsylvania & 69 & 9 & 69 & 0 \\
\hline Rhode Island & 60 & 0 & 60 & 0 \\
\hline South Carolina & 13 & 43 & 7 & 41 \\
\hline South Dakota & 0 & 100 & 0 & 100 \\
\hline Tennessee & 45 & 20 & 34 & 5 \\
\hline Texas & 0 & 94 & 0 & 93 \\
\hline Utah & 21 & 45 & 3 & 17 \\
\hline Vermont & 7 & 21 & 0 & 0 \\
\hline Virginia & 18 & 57 & 8 & 41 \\
\hline Washington & 5 & 64 & 0 & 56 \\
\hline West Virginia & 62 & 27 & 58 & 4 \\
\hline Wisconsin & 8 & 74 & 0 & 65 \\
\hline Wyoming & 0 & 74 & 0 & 70 \\
\hline USA & 19 & 60 & 14 & 51 \\
\hline
\end{tabular}


There is evidence from other studies that rates of drug-related death are elevated among males [64]. Here, we find a correlation of 0.55 at state level between the ratio (in 2016) of male to female opioid age standardized death rates and the proportion of counties in each state classed as high risk cluster centers in Table 2. This relationship, shown graphically in Figure 2, suggests that analysis of drug deaths by gender would show high risk clustering as especially apparent for males.

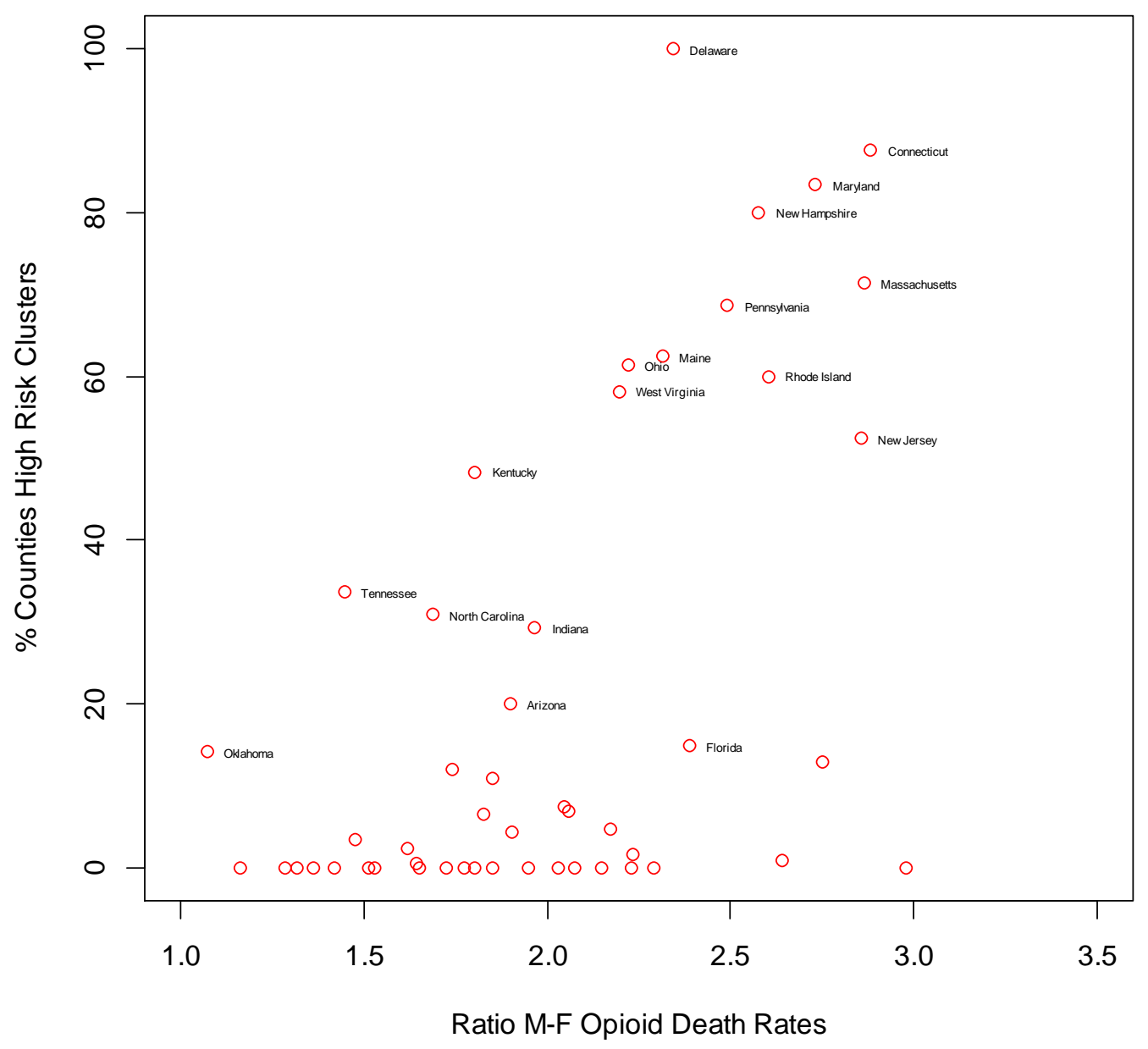

Figure 2. Male-female opioid mortality ratio and high risk drug death clustering.

\subsection{Spatially Varying Coefficients}

When geographic heterogeneity in covariate impacts is allowed for (in the better fitting unemployment model), we find a major gain in fit, with the WAIC reduced to 18,329 . Table 3 summarizes the coefficient variation (for the five covariates which are observed at county level) in terms of averages for the nine US Census Divisions.

It can be seen that the average effects of unemployment and segregation are attenuated as compared to Table 1, whereas average impacts of income disparity, social capital, and rurality are enhanced. Regarding contrasts between Divisions, one can see a different explanatory pattern in (say) the Pacific Division, where, compared to the average, social capital and rurality are more important, and income disparities and segregation less important, as influences on drug death rates. 
Table 3. Varying Predictor Effects according to US Census Divisions (Posterior Mean Effects and $95 \%$ Intervals).

\begin{tabular}{|c|c|c|c|c|c|c|c|c|c|}
\hline & & Mean & $2.5 \%$ & $97.5 \%$ & & & Mean & $2.5 \%$ & $97.5 \%$ \\
\hline \multirow{10}{*}{ Unemployment } & Divn 1 & 0.13 & -0.05 & 0.33 & \multirow{10}{*}{$\begin{array}{c}\text { Income } \\
\text { Disparity } \\
\text { (ICE Index) }\end{array}$} & Divn 1 & -0.79 & -1.05 & -0.48 \\
\hline & Divn 2 & 0.09 & -0.07 & 0.27 & & Divn 2 & -0.78 & -0.96 & -0.54 \\
\hline & Divn 3 & 0.09 & -0.02 & 0.26 & & Divn 3 & -0.78 & -0.93 & -0.62 \\
\hline & Divn 4 & 0.11 & 0.01 & 0.28 & & Divn 4 & -0.80 & -0.99 & -0.66 \\
\hline & Divn 5 & 0.05 & -0.08 & 0.22 & & Divn 5 & -0.74 & -0.89 & -0.57 \\
\hline & Divn 6 & 0.06 & -0.05 & 0.23 & & Divn 6 & -0.75 & -0.89 & -0.59 \\
\hline & Divn 7 & 0.11 & -0.01 & 0.28 & & Divn 7 & -0.77 & -0.94 & -0.61 \\
\hline & Divn 8 & 0.14 & 0.02 & 0.31 & & Divn 8 & -0.82 & -1.02 & -0.67 \\
\hline & Divn 9 & -0.09 & -0.32 & 0.14 & & Divn 9 & -0.51 & -0.74 & -0.34 \\
\hline & US average & 0.08 & -0.01 & 0.24 & & US average & -0.75 & -0.93 & -0.59 \\
\hline \multirow{10}{*}{ Social Capital } & Divn 1 & -0.54 & -1.10 & 0.04 & \multirow{10}{*}{ Rurality } & Divn 1 & -0.41 & -0.52 & -0.27 \\
\hline & Divn 2 & -0.53 & -1.10 & -0.01 & & Divn 2 & -0.41 & -0.51 & -0.32 \\
\hline & Divn 3 & -0.50 & -1.05 & -0.03 & & Divn 3 & -0.43 & -0.50 & -0.34 \\
\hline & Divn 4 & -0.50 & -1.04 & -0.07 & & Divn 4 & -0.44 & -0.53 & -0.33 \\
\hline & Divn 5 & -0.51 & -1.07 & -0.04 & & Divn 5 & -0.40 & -0.45 & -0.34 \\
\hline & Divn 6 & -0.51 & -1.06 & -0.05 & & Divn 6 & -0.39 & -0.45 & -0.33 \\
\hline & Divn 7 & -0.49 & -1.02 & -0.05 & & Divn 7 & -0.39 & -0.48 & -0.31 \\
\hline & Divn 8 & -0.47 & -1.02 & -0.03 & & Divn 8 & -0.44 & -0.55 & -0.35 \\
\hline & Divn 9 & -0.73 & -1.45 & -0.15 & & Divn 9 & -0.55 & -0.72 & -0.39 \\
\hline & US average & -0.53 & -1.10 & -0.06 & & US average & -0.43 & -0.50 & -0.36 \\
\hline \multirow{10}{*}{ Segregation } & Divn 1 & 0.22 & 0.00 & 0.41 & \multicolumn{5}{|c|}{ Definitions } \\
\hline & Divn 2 & 0.21 & 0.04 & 0.36 & Division 1 & \multicolumn{4}{|c|}{ New England } \\
\hline & Divn 3 & 0.20 & 0.08 & 0.32 & Division 2 & \multicolumn{4}{|c|}{$\begin{array}{l}\text { Mid-Atlantic (New Jersey, } \\
\text { New York, Pennsylvania) }\end{array}$} \\
\hline & Divn 4 & 0.17 & 0.05 & 0.29 & Division 3 & \multicolumn{4}{|c|}{$\begin{array}{c}\text { East North Central } \\
\text { (Illinois, Indiana, Michigan, Ohio, Wisc) }\end{array}$} \\
\hline & Divn 5 & 0.19 & 0.03 & 0.33 & Division 4 & \multicolumn{4}{|c|}{ West North Central } \\
\hline & Divn 6 & 0.18 & 0.05 & 0.33 & Division 5 & \multicolumn{4}{|c|}{ South Atlantic } \\
\hline & Divn 7 & 0.14 & 0.02 & 0.29 & Division 6 & \multicolumn{4}{|c|}{$\begin{array}{c}\text { East South Central } \\
\text { (Alab., Kentucky, Miss., Tennessee) }\end{array}$} \\
\hline & Divn 8 & 0.16 & -0.02 & 0.31 & Division 7 & \multicolumn{4}{|c|}{$\begin{array}{c}\text { West South Central } \\
\text { (Ark., Louisiana, Okl., Texas) }\end{array}$} \\
\hline & Divn 9 & 0.10 & -0.20 & 0.37 & Division 8 & \multicolumn{4}{|c|}{ Mountain } \\
\hline & US average & 0.17 & 0.03 & 0.31 & Division 9 & \multicolumn{4}{|c|}{$\begin{array}{l}\text { Pacific (Alaska, California, } \\
\text { Hawaii, Oregon, Washington) }\end{array}$} \\
\hline
\end{tabular}

\section{Discussion}

Analysis of small area contrasts in drug-related deaths has raised differing themes according to the country where research takes place. In the US, where there is extensive ecological research into drug-related deaths, different phases (with different causal influences) have been identified $[41,65]$.

Thus, Zoorob [65] highlights the role of fentanyl in recent increases in drug-related mortality. Since fentanyl access is higher in the Eastern US, Zoorob argues that "the epicenter of the overdose crisis shifted towards the eastern United States over these years" as part of the third wave of the overdose epidemic. A similar trend, looking at changes in the clustering of high risk of drug death, is identified by Wilt et al. [51].

In terms of implications for intervention and funding, drug law enforcement [66], and drug abuse prevention, the locations of high risk clusters are important. The analysis above (e.g., see Figure 1) is consistent with findings by other studies in showing a geographic skew in high risk clustering towards the east and northeast of the US, while most of the rest of the US is low risk. A spatial concentration of drug-related deaths appears in studies of other countries [28]. 
The clustering analysis in our US study is conditional on a particular regression model. In this model, relative risks of drug death in different US counties are modeled as a function of income disparity within counties, job availability, social capital, levels of rurality, racial segregation, and measures of supply. None of these risk factors have a predominant influence. By contrast, many explanations are predominantly uni-causal. For example, the "deaths of despair" concept places a strong emphasis on the loss of traditional employment opportunities.

Regarding the research evidence on employment availability, a number of US studies find unemployment, or unemployment increases, to be associated with drug-related mortality or related outcomes [19,67], and there are reports of similar findings in other high-income societies such as Australia [68]. At the individual level, psychological distress is proposed as a mediator variable [69].

However, the analysis here, while finding unemployment, and increases in unemployment, to have a significant influence on raising drug-related deaths (at least before allowing for coefficient variation), does not show an overwhelming impact for these variables. Rather, factors such as social capital, income levels, race segregation, and drug supply are also important. An urban bias to US drug-related deaths is also confirmed. Thus, the evidence here is of a set of relevant area risk factors, as against a uni-causal explanation.

Support for a more nuanced multifactorial explanation of US trends is provided by recent overviews $[29,70,71]$, stressing the impact of social as well as economic conditions, of community resilience, and of supply as well as demand factors. Thus, quoting [29], "strong communities offer resilience against drug epidemics".

The same relevance of social environment is true of other high-income countries where ecological studies of drug death have been carried out. A study of drug deaths in Scotland [28], where drug-related deaths have risen as fast as they have in the US, showed that the impact of deprivation on drug-related deaths is moderated by social cohesion, which is measured inversely by an index of social fragmentation. Work on opioid use in Australia stresses the role of both demand and supply factors [72] and community resilience [73].

The analysis in this paper has had to allow for a relatively high rate of missing data (non-release of small death counts, namely counts under 10). The counties affected are mainly rural counties with small populations. One strategy [74] is to omit such counties from the analysis, but such a "complete cases" analysis may lead to bias [75], and may in particular affect inferences about area characteristics which affect missing data rates. Thus, [74] report higher drug deaths in rural counties, whereas the present analysis, which explicitly models the missing data mechanism, finds rural areas to have lower drug mortality.

\section{Conclusions}

Pronounced intra-national variations in drug-related mortality parallel international differences; see, for example, the studies [32,76] on Canada and Italy, respectively. There are unique national aspects to explaining contextual variations. For example, fentanyl supply is most important in the US and Canada [76], whereas in Germany, supplies of methamphetamine are important [77]. However, common themes are also apparent, such as community resilience offsetting impacts of job loss, area socioeconomic status, or area poverty.

The present study on US small area variations supports a multifactorial explanation, with area income levels (and income disparity within areas) and social capital as paramount influences. Rurality is also a significant influence and has a negative impact when other area risk factors are controlled for (i.e., when correlations between area predictors are controlled in regression). The analysis here downplays the impacts of unemployment or unemployment change, especially when geographic heterogeneity in predictor impacts is allowed for in a spatially varying coefficients model. We also find a considerable geographic skew in the location of high risk clustering in the US [78].

The analysis is subject to certain limitations. The first, and one that must always be acknowledged with regard to ecological (area) studies, is that causal influences regarding individual health risk factors 
cannot be inferred from ecological studies. On the other hand, there is strong evidence that place (or contextual) effects per se, and interactions between individuals and environments, are relevant to explaining geographic variations in drug deaths $[9,79]$.

A further caveat to making international comparisons in contextual effects is that the international evidence base on contextual variation in drug-related mortality is relatively limited. There are considerable research gaps in the small area study of drug-related deaths, with the great majority of studies being for the US.

Other caveats with regard to the US analysis concern especially the available data. First, and as noted by [80], "the methods used to classify deaths on death certificates may be leading to a substantial undercount of these deaths [in the US]", and later, "about $25 \%$ of U.S. overdose deaths had no drugs specified on the death certificate, so it is likely that national statistics underestimate by a substantial fraction the number of opioid analgesic- and heroin-related deaths". The second problem with the data is the non-release of small death counts (counts under 10), so conclusions obtained may be affected by the strategy used to deal with this.

Funding: This research received no external funding.

Conflicts of Interest: The authors declare no conflict of interest.

\section{Appendix A. Regression Methods}

We adopt Bayesian disease mapping, namely a form of generalized linear model to estimate relative risks of drug-related mortality in different areas. The response is the number of deaths in each county over a 3-year period (2015-2017), and a Poisson regression is adopted, with a log link model incorporating risk factors $X_{i}$ for county $i$ (e.g., unemployment rates) [78]. For some counties, the death data are missing (see Appendix B), necessitating specialized techniques. The regression includes random effects to reflect spatially structured but unobserved risk factors, and also a separate set of random effects to take account of Poisson over-dispersion-since the variance of the death counts $(50,987)$ exceeds the average count $(105)$.

Thus, for counts $Y_{\mathrm{i}}$ of drug-related deaths for counties $i=1, \ldots, N$

$$
\begin{gathered}
Y_{i} \sim \operatorname{Poisson}\left(E_{i} \rho_{i}\right) \\
\log \left(\rho_{i}\right)=X_{i} \beta+s_{i}+u_{i}
\end{gathered}
$$

where $E_{i}$ are expected drug deaths, $\rho_{i}$ is the relative risk of drug death for county $i, \beta$ are regression coefficients for risk factors, $s_{i}$ are random effects representing unobserved but spatially correlated risk factors, and $u_{i}$ are iid random effects. Expected deaths are known offsets obtained by multiplying county populations in 2016 by US-wide age-specific drug death rates. The random effects $s_{i}$ are assumed to follow the scheme of Besag et al. [81], in which the spatial effect for area $i$ depends on spatial effects in adjacent areas. The predictors $X$ are all converted to a $[0,1]$ scale, so that their relative importance as risk factors can be assessed.

In the spatially varying coefficients model, the regression effect for predictor $\mathrm{p}$ and county $i$ is specified as $b_{p i}=\beta_{p}+s_{p i}$, where the $s_{p i}$ are zero mean spatial effects as in [81], and $\beta_{p}$ is a fixed effect. This is implemented in WINBUGS using the car.normal function for spatially correlated effects.

The data are overdispersed relative to the Poisson, with mean death count exceeding the variance. One option is a negative binomial model instead. However, the negative binomial is one of a broader class that can be obtained by introducing multiplicative random effects into a Poisson model $[82,83]$. Thus, one has that the Poisson means for incidence are specified by

$$
\mu_{i}=E_{i} \rho_{i} \lambda_{i}
$$


where $\lambda_{i}$ are positive random effects. For the Poisson-gamma model (equivalent to a negative binomial), the $\lambda_{i}$ are gamma distributed with mean 1 . Another option is to take $\log \left(\lambda_{i}\right)$ as normally distributed, leading to a Poisson-lognormal model for overdispersion. Specifically, under the log-link in (A1)-(A2), we have that $u_{i}=\log \left(\lambda_{i}\right)$ is normal, giving a Poisson-lognormal.

\section{Appendix B. Missing Death Data}

In counties with death counts $Y_{i}$ not supplied (the CDC Wonder site does not release death totals under 10), the sampling of the missing totals $Y_{i}$ is subject to an upper threshold of 9. Expected counts are known for these counties, and sampling is from the relative risk model (A1), so taking account of known covariates for these counties, and also borrowing strength from neighboring counties, thereby accounting for spatial correlation in unknown factors affecting relative risks. A model for informative (or non-ignorable) missing data is also adopted [84], since the chance of death data being missing is clearly related to the size of the death count that would have been observed in the absence of thresholding. The probability of a count being missing is related to two covariates: $Z_{1}$, a binary indicator, from (A1), of whether $\rho_{i}$ exceeds 1 ; and $Z_{2}$, the proportion rural in the county, since rural counties tend to have both low relative risks and low populations.

We carry out a logit regression with response $M_{i}=1$ for missing mortality counts, and $M_{i}=0$ otherwise. We expect the chance of a missing response to be negatively related to the binary indicator of high relative risk, and positively related to the county percent rural. Note that this is a selection model [84], with the chance of missing data conditional on the modeled mortality outcome. Thus, for the best fitting model under (A1), with unemployment rates to represent employment opportunities, we find posterior means (sd) for coefficients on $Z_{1}$ and $Z_{2}$ to be $-4.15(0.26)$ and $4.83(0.22)$, respectively.

One way of gauging the success of the modeling strategy is to compare estimated relative risks at state level (from the model) with the age-adjusted death rates (over 2015-2017) from the CDC Wonder site. State death totals are not affected by any thresholding of death counts. The estimated state level relative risks are obtained by summing the Poisson county level model means $\mu_{i}=E_{i} \rho_{i}$ and expected deaths $E_{i}$ within states $j=1, \ldots, 51$ and comparing the resulting two summed totals. We find a correlation of 0.996 between the 51 age-adjusted death rates and the estimated state relative risks of drug death (see Appendix B Table A1). There is a correlation of 0.999 between the moment estimators $Y_{j} / E_{j}$ of relative risk at state level and the modeled estimates $\mu_{j} / E_{j}$. 
Table A1. Age Adjusted Death Rates and Modelled Relative Risks for US States (2015-2017).

\begin{tabular}{|c|c|c|c|c|c|}
\hline & Deaths & $\begin{array}{l}\text { Age Adjusted Death } \\
\text { Rate per } 100,000\end{array}$ & Total $\mu$ & $\begin{array}{c}\text { Total } \\
\text { Expected Deaths }\end{array}$ & $\begin{array}{c}\text { Modelled } \\
\text { Relative Risk }\end{array}$ \\
\hline Alaska & 397 & 17.7 & 387.0 & 437.8 & 0.88 \\
\hline Alabama & 2327 & 16.6 & 2389.0 & 2814.6 & 0.85 \\
\hline Arkansas & 1239 & 14.4 & 1288.2 & 1693.8 & 0.76 \\
\hline Arizona & 4188 & 20.5 & 4185.0 & 3811.6 & 1.10 \\
\hline California & 14,181 & 11.4 & $14,188.2$ & $22,966.6$ & 0.62 \\
\hline Colorado & 2826 & 16.5 & 2796.7 & 3219.3 & 0.87 \\
\hline Connecticut & 2843 & 26.8 & 2838.9 & 2127.2 & 1.33 \\
\hline Distr. Columbia & 704 & 33.9 & 695.1 & 430.8 & 1.61 \\
\hline Delaware & 818 & 29.9 & 822.5 & 543.8 & 1.51 \\
\hline Florida & 13,044 & 21.7 & $13,032.9$ & $11,544.2$ & 1.13 \\
\hline Georgia & 4233 & 13.6 & 4294.6 & 5958.2 & 0.72 \\
\hline Hawaii & 563 & 12.6 & 560.1 & 827.8 & 0.68 \\
\hline Iowa & 964 & 10.8 & 994.8 & 1760.4 & 0.57 \\
\hline Idaho & 697 & 14.6 & 681.4 & 913.9 & 0.75 \\
\hline Illinois & 7024 & 18.2 & 7043.5 & 7595.5 & 0.93 \\
\hline Indiana & 4623 & 24.3 & 4661.5 & 3801.5 & 1.23 \\
\hline Kansas & 975 & 11.6 & 974.3 & 1642.4 & 0.59 \\
\hline Kentucky & 4258 & 33.6 & 4223.5 & 2580.1 & 1.64 \\
\hline Louisiana & 2965 & 21.8 & 2943.1 & 2708.6 & 1.09 \\
\hline Massachusetts & 6119 & 30.1 & 6117.3 & 4047.6 & 1.51 \\
\hline Maryland & 5576 & 30.1 & 5555.0 & 3574.3 & 1.55 \\
\hline Maine & 1046 & 28.1 & 1074.9 & 786.8 & 1.37 \\
\hline Michigan & 7021 & 24.2 & 7089.5 & 5754.9 & 1.23 \\
\hline Minnesota & 1986 & 12.1 & 1993.3 & 3189.8 & 0.62 \\
\hline Missouri & 3804 & 21.6 & 3828.9 & 3508.5 & 1.09 \\
\hline Mississippi & 1057 & 12.2 & 1106.3 & 1709.6 & 0.65 \\
\hline Montana & 376 & 12.4 & 369.1 & 586.4 & 0.63 \\
\hline North Carolina & 5937 & 19.9 & 5977.8 & 5829.5 & 1.03 \\
\hline North Dakota & 206 & 9.5 & 187.0 & 421.1 & 0.44 \\
\hline Nebraska & 398 & 7.2 & 406.2 & 1066.4 & 0.38 \\
\hline New Hampshire & 1370 & 36.8 & 1372.1 & 796.9 & 1.72 \\
\hline New Jersey & 6195 & 23.2 & 6195.3 & 5310.5 & 1.17 \\
\hline New Mexico & 1494 & 25.1 & 1456.4 & 1183.6 & 1.23 \\
\hline Nevada & 1960 & 21.2 & 1930.5 & 1686.5 & 1.14 \\
\hline New York & 10,313 & 17 & $10,370.9$ & $11,799.5$ & 0.88 \\
\hline Ohio & 12,750 & 38.5 & $12,811.0$ & 6730.3 & 1.90 \\
\hline Oklahoma & 2313 & 20.2 & 2265.4 & 2212.0 & 1.02 \\
\hline Oregon & 1541 & 12.1 & 1570.6 & 2352.8 & 0.67 \\
\hline Pennsylvania & 13,279 & 36.1 & $13,305.5$ & 7479.3 & 1.78 \\
\hline Rhode Island & 956 & 30 & 960.1 & 625.6 & 1.53 \\
\hline South Carolina & 2648 & 18.1 & 2698.7 & 2805.4 & 0.96 \\
\hline South Dakota & 207 & 8.4 & 194.4 & 477.8 & 0.41 \\
\hline Tennessee & 4863 & 24.5 & 4878.3 & 3836.3 & 1.27 \\
\hline Texas & 8408 & 10 & 8459.9 & $15,645.0$ & 0.54 \\
\hline Utah & 1931 & 22.6 & 1910.3 & 1611.7 & 1.19 \\
\hline Virginia & 3951 & 15.7 & 3999.4 & 4969.9 & 0.80 \\
\hline Vermont & 358 & 20.7 & 371.3 & 369.2 & 1.01 \\
\hline Washington & 3365 & 14.8 & 3354.9 & 4215.7 & 0.80 \\
\hline Wisconsin & 3129 & 18.6 & 3131.8 & 3351.2 & 0.93 \\
\hline West Virginia & 2583 & 50.3 & 2525.5 & 1075.8 & 2.35 \\
\hline Wyoming & 264 & 15.4 & 258.7 & 338.8 & 0.76 \\
\hline USA & 186,273 & 19.3 & $186,726.7$ & $186,726.7$ & 1.0 \\
\hline
\end{tabular}


The WINBUGS code for the model is model $\{$ for $(i$ in $1: \mathrm{N})\{\mathrm{Y}[i] \sim \operatorname{dpois}(\mathrm{mu}[i]) \mathrm{I}(, \mathrm{U}[i])$

$\mathrm{mu}[i]<-\mathrm{E}[i] *$ rho $[i]$

\# Indicator for high relative risk

high.rho[i] $<-$ step(rho[i]-1)

\# Clustering indicators (posterior means are estimates of probabilities)

hihi $[i]<-$ step $($ rho $[i]-1){ }^{*}$ step (Locality.rho[i]-1)

lolo $[i]<-\operatorname{step}(1-$ rho $[i]) *$ step $(1-$ Locality.rho $[i])$

hilo[i] <-step $($ rho[i]-1) * step $(1-$ Locality.rho[i])

lohi $[\mathrm{i}]<-\operatorname{step}(1-\mathrm{rho}[i]){ }^{*}$ step(Locality.rho[i]-1)

\# Locality average relative risk. cum.num are cumulative locality sizes

Locality.rho[i] <-sum(rho.adj[cum.num[i] + 1:cumnum[i +1$]]) /$ num $[i])$

\# Relative Risk Model

$\log (\operatorname{rho}[i])<-$ alpha $+\operatorname{inprod}(\operatorname{beta}[], X[i])+,\mathrm{s}[i]+\mathrm{u}[i]$

\# unstructured (iid) random errors

$\mathrm{u}[i] \sim \operatorname{dnorm}(0$, tau.u $)$

\# Missing Data Model

$\mathrm{M}[i] \sim \operatorname{dbern}(\mathrm{pi}[i])$

$\mathrm{Z}[i, 1]<-$ high.rho $[i]$

logit(pi $[i])<-$ alpha.M + inprod(gamma[], Z[i,])\}

\# \% of residual variation spatially structured

shspat $<-100 *(\operatorname{sd}(\mathrm{s}[]) * \operatorname{sd}(\mathrm{s}[\mathrm{l})) /(\operatorname{sd}(\mathrm{s}[]) * \operatorname{sd}(\mathrm{s}[])+\operatorname{sd}(\mathrm{u}[]) * \mathrm{sd}(\mathrm{u}[\mathrm{l}))$

\# Model for spatial random errors $s[i]$

\# num[i] are numbers of neighbours of county $i$, adj is adjacency list

\# NN is sum of num[i].

for $(i$ in $1: \mathrm{NN})\{$ weights $[i]<-1$; $\operatorname{rho} . \operatorname{adj}[i]<-\operatorname{rho}[\operatorname{adj}[i]]\}$

s [1:N] car.normal(adj[], weights[], num[], tau.s)

\# Priors on Hyperparameters

tau.u $\sim$ dgamma $(1,0.01)$; tau.s $\sim$ dgamma $(1,0.01)$

alpha $\sim \operatorname{dnorm}(0,0.01) ;$ alpha.M $\sim \operatorname{dnorm}(0,0.01)$

for $(j$ in $1: 2)\{$ gamma $[j] \sim \operatorname{dnorm}(0,0.1)\}$

for $(j$ in $1: 7)\{$ beta[j] $~ \operatorname{dnorm}(0,0.1)\}\}$

The vector $Y[]$ has NA for counties with missing responses; the vector $U$ is set to 9 for these counties and to Yi when the death count is above the threshold of 9 . The vectors adj and num can be derived in $\mathrm{R}$ by first inputting a shapefile using the maptools command, shape = readShapePoly(("shape.shp"), then using commands poly $=$ poly $2 \mathrm{nb}$ (shape) and $\mathrm{WB}=\mathrm{nb} 2 \mathrm{WB}$ (poly) to create lists WB\$adj and WB\$num. The vector cum.num can be obtained in $\mathrm{R}$ as

cum.num $=\mathrm{c}()$; cum.num $[1]=0$

cums $=$ cumsum $(\mathrm{WB} \$$ num $)$

for $(j$ in $1: \mathrm{N})\{$ cum.num $[j+1]=\operatorname{cums}[j]\}$

\section{References}

1. United Nations Office on Drugs and Crime (UNODC). Part 2 Global Overview of Drug Demand and Supply. In World Drug Report; United Nations Office on Drugs and Crime: Vienna, Austria, 2019.

2. Degenhardt, L.; Charlson, F.; Ferrari, A.; Santomauro, D.; Erskine, H.; Mantilla-Herrara, A. The global burden of disease attributable to alcohol and drug use in 195 countries and territories, 1990-2016: A systematic analysis for the Global Burden of Disease Study 2016. Lancet Psychiatry 2018, 5, 987-1012. [CrossRef]

3. Xibiao, Y.; Jenny, S.; Bonnie, H.; Mark, T.; William, K. At-a-glance-Impact of drug overdose-related deaths on life expectancy at birth in British Columbia. Health Promot. Chronic Dis. Prev. Can. Res. Policy Pract. 2018, 38, 248. 
4. $\quad$ Leung, M. The Opioid Crisis: The United States and Canada's Fentanyl Epidemic. 2019, THE Wilson Centre. Available online: https://www.wilsoncenter.org/article/the-opioid-crisis-the-united-states-and-canadasfentanyl-epidemic (accessed on 2 April 2020).

5. United Nations Office on Drugs and Crime (UNODC). Part 3 Depressants. In World Drug Report; United Nations Office on Drugs and Crime: Vienna, Austria, 2019.

6. Centre for Disease Control. Drug Overdose Mortality by State. 2019, CDC, Washington. Available online: https://www.cdc.gov/nchs/pressroom/sosmap/drug_poisoning_mortality/drug_poisoning.htm (accessed on 10 April 2020).

7. National Records of Scotland. Drug Related Deaths in Scotland in 2018; National Records of Scotland: Edinburgh, Scotland, 2019.

8. Cooper, H.; Bossak, B.; Tempalski, B.; Des Jarlais, D.; Friedman, S. Geographic approaches to quantifying the risk environment: Drug-related law enforcement and access to syringe exchange programmes. Int. J. Drug Policy 2009, 20, 217-226. [CrossRef] [PubMed]

9. Rhodes, T. Risk environments and drug harms: A social science for harm reduction approach. Int. J. Drug Policy 2009, 20, 193-201. [CrossRef]

10. Macintyre, S.; Ellaway, A. Neighborhoods and health: An overview. In Neighborhoods and Health; Kawachi, I., Berkman, L., Eds.; Oxford University Press: New York, NY, USA, 2003; pp. 20-44.

11. Pemberton, S.; Humphris, P. Locality, Neighborhood and Health: A Literature Review; IRiS Working Paper Series; No. 13/2016; UPWEB Working Paper Series; No. 2/2016; Institute for Research into Superdiversity: Birmingham, UK, 2016.

12. Twigg, L. Geographies of space, place, and population health. In The Wiley Blackwell Encyclopedia of Health, Illness, Behavior, and Society; Wiley-Blackwell: Hoboken, NJ, USA, 2014; pp. 726-731.

13. Bambra, C.; Smith, K.; Pearce, J. Scaling up: The politics of health and place. Soc. Sci. Med. 2019, 232, 36-42. [CrossRef]

14. You, H.; Ha, J.; Kang, C.; Kim, L.; Kim, J.; Shen, J.; Park, S.; Chun, S.; Hwang, J.; Yamashita, T.; et al. Regional variation in states' naloxone accessibility laws in association with opioid overdose death rates-Observational study (STROBE compliant). Medicine 2020, 99, e20033. [CrossRef]

15. Kang, S.; Cramb, S.; White, N.; Ball, S.; Mengersen, K. Making the most of spatial information in health: A tutorial in Bayesian disease mapping for areal data. Geospat. Health 2016, 11, 190-198. [CrossRef]

16. Dasgupta, N.; Beletsky, L.; Ciccarone, D. Opioid crisis: No easy fix to its social and economic determinants. Amer. J. Public Health 2018, 108, 182-186. [CrossRef]

17. Case, A.; Deaton, A. Mortality and morbidity in the 21st century. Brook. Pap. Econ. Act. 2017, 2017, 397-476. [CrossRef]

18. Burns, H. GDP and the economics of despair (Editorial). Brit. Med. J. 2018, 360, k1239. [CrossRef]

19. Hollingsworth, A.; Ruhm, C.; Simon, K. Macroeconomic conditions and opioid abuse. J. Health Econ. 2017, 56, 222-233. [CrossRef]

20. Stein, E.; Gennuso, K.; Ugboaja, D.; Remington, P. The epidemic of despair among White Americans: Trends in the leading causes of premature death, 1999-2015. Am. J. Public Health 2017, 107, 1541-1547. [CrossRef] [PubMed]

21. Dean, A.; Kimmel, S. Free trade and opioid overdose death in the United States. SSM Popul. Health 2019, 8, 100409. [CrossRef]

22. Ruhm, C. Deaths of despair or drug problems? Natl. Bur. Econ. Res. 2018. [CrossRef]

23. Boardman, J.; Finch, B.; Ellison, C.; Williams, D.; Jackson, J. Neighborhood Disadvantage, Stress, and Drug Use among Adults. J. Health Soc. Behav. 2001, 42, 151-165. [CrossRef]

24. Monnat, S. Factors associated with county-level differences in US drug-related mortality rates. Am. J. Prev. Med. 2018, 54, 611-619. [CrossRef]

25. Shah, R.; Uren, Z.; Baker, A.; Majeed, A. Trends in deaths from drug overdose and poisoning in England and Wales 1993-1998. J. Public Health 2001, 23, 242-246. [CrossRef]

26. House of Commons Scottish Affairs Committee. Problem Drug Use in Scotland; House of Commons: London, UK, 2019.

27. Bruhn, H. The Group Effect: Social Cohesion and Health Outcomes; Springer: New York, NY, USA, 2009.

28. Congdon, P. Assessing Persistence in Spatial Clustering of Disease, with an Application to Drug Related Deaths in Scottish Neighborhoods. Epidemiol. Biostat. Public Health 2019, 16. [CrossRef] 
29. Zoorob, M.; Salemi, J. Bowling alone, dying together: The role of social capital in mitigating the drug overdose epidemic in the United States. Drug Alcohol Depend. 2017, 173, 1-9. [CrossRef] [PubMed]

30. Åslund, C.; Nilsson, K. Social capital in relation to alcohol consumption, smoking, and illicit drug use among adolescents: A cross-sectional study in Sweden. Int. J. Equity Health 2013, 12, 33. [CrossRef]

31. Rupasingha, A.; Goetz, S.; Freshwater, D. The production of social capital in US counties. J. Socio-Econ. 2006, 35, 83-101. [CrossRef]

32. Gatti, U.; Tremblay, R.; Schadee, H. Community characteristics and death by homicide, suicide and drug overdose in Italy: The role of civic engagement. Eur. J. Crim. Policy Res. 2007, 13, 255-275. [CrossRef]

33. Cooper, H.; Friedman, S.; Tempalski, B.; Friedman, R. Residential segregation and injection drug use prevalence among Black adults in US metropolitan areas. Am. J. Public Health 2007, 97, 344-352. [CrossRef]

34. Frankenfeld, C.; Leslie, T. County-level socioeconomic factors and residential racial, Hispanic, poverty, and unemployment segregation associated with drug overdose deaths in the United States, 2013-2017. Ann. Epidemiol. 2019, 35, 12-19. [CrossRef]

35. Galea, S.; Ahern, J.; Vlahov, D.; Coffin, P.; Fuller, C.; Leon, A.; Tardiff, K. Income distribution and risk of fatal drug overdose in New York City neighborhoods. Drug Alcohol Depend. 2003, 70, 139-148. [CrossRef]

36. Ompad, D.; Fuller, C. The urban environment, drug use, and health. In Handbook of Urban Health; Galea, S., Vlahov, D., Eds.; Springer: Boston, MA, USA, 2005; pp. 127-154.

37. Barnum, J.D.; Campbell, W.L.; Trocchio, S.; Caplan, J.; Kennedy, L. Examining the environmental characteristics of drug dealing locations. Crime Delinq. 2017, 63, 1731-1756. [CrossRef]

38. Hedegaard, H.; Miniño, A.; Warner, M. Urban-Rural Differences in Drug Overdose Death Rates, by Sex, Age, and Type of Drugs Involved, 2017; NCHS Data Brief 345; NCHS: Washington, DC, USA, 2019.

39. Monnat, S. The contributions of socioeconomic and opioid supply factors to US drug mortality rates: Urban-rural and within-rural differences. J. Rural Stud. 2019, 68, 319-335. [CrossRef]

40. Ruhm, C. Deaths of Despair or Drug Problems; NBER Working Papers 24188; National Bureau of Economic Research: Cambridge, MA, USA, 2018.

41. DeWeerdt, S. Tracing the US opioid crisis to its roots. Nature 2019, 573, S10. [CrossRef]

42. Giraudon, I.; Lowitz, K.; Dargan, P.; Wood, D.; Dart, R. Prescription opioid abuse in the UK. Br. J. Clin. Pharmacol. 2013, 76, 823-824. [CrossRef]

43. Clarke, H.; Bao, J.; Weinrib, A.; Dubin, R.; Kahan, M. Canada's hidden opioid crisis: The health care system's inability to manage high-dose opioid patients: Fallout from the 2017 Canadian opioid guidelines. Can. Fam. Physician 2019, 65, 612-614.

44. Hedegaard, H.; Miniño, A.; Warner, M. Drug Overdose Deaths in the United States, 1999-2018; NCHS Data Brief No. 356; NCHS: Washington, DC, USA, 2020.

45. Best, N.; Arnold, N.; Thomas, A.; Waller, L.; Conlon, E. Bayesian models for spatially correlated disease and exposure data. In Proceedings of the Bayesian Statistics 6: The Sixth Valencia International Meeting, Valencia, Spain, 1-5 June 1999; Volume 6.

46. Richardson, S.; Thomson, A.; Best, N.; Elliott, P. Interpreting posterior relative risk estimates in disease-mapping studies. Environ. Health Perspect. 2004, 112, 1016-1025. [CrossRef]

47. Chiou, Y.; Jou, R.; Yang, C. Factors affecting public transportation usage rate: Geographically weighted regression. Transp. Res. Part A Policy Pract. 2015, 78, 161-177. [CrossRef]

48. Fotheringham, A.; Yang, W.; Kang, W. Multiscale geographically weighted regression (MGWR). Ann. Am. Assoc. Geogr. 2017, 107, 1247-1265. [CrossRef]

49. Assunçao, R. Space varying coefficient models for small area data. Environmetrics 2003, 14, 453-473. [CrossRef]

50. Wheeler, D.; Waller, L. Comparing spatially varying coefficient models: A case study examining violent crime rates and their relationships to alcohol outlets and illegal drug arrests. J. Geogr. Syst. 2009, 11, 1-22. [CrossRef]

51. Kerry, R.; Yoo, E.; Ingram, B. Spatial analysis of drug poisoning deaths in the American west: A comparison study using profile regression to adjust for collinearity and spatial correlation. Drug Alcohol Depend. 2019, 204, 107598. [CrossRef]

52. Stewart, K.; Cao, Y.; Hsu, M.; Artigiani, E.; Wish, E. Geospatial analysis of drug poisoning deaths involving heroin in the USA, 2000-2014. J. Urban Health 2017, 94, 572-586. [CrossRef]

53. Anselin, L. Local indicators of spatial association-LISA. Geogr. Anal. 1995, 27, 93-115. [CrossRef] 
54. Wilt, G.; Lewis, B.; Adams, E. Peer Reviewed: A Spatial Exploration of Changes in Drug Overdose Mortality in the United States, 2000-2016. Prev. Chronic Dis. 2019, 16. [CrossRef]

55. Krieger, N.; Kim, R.; Feldman, J.; Waterman, P. Using the Index of Concentration at the Extremes at multiple geographical levels to monitor health inequities in an era of growing spatial social polarization: Massachusetts, USA (2010-14). Int. J. Epidemiol. 2018, 47, 788-819. [CrossRef]

56. U.S. Drug Enforcement Administration, Diversion Control Division. National Forensic Laboratory Information System: 2016 Midyear Report; Drug Enforcement Administration: Springfield, VA, USA, 2017.

57. Lippold, K.; Jones, C.; Olsen, E.; Giroir, B. Racial/ethnic and age group differences in opioid and synthetic opioid-involved overdose deaths among adults aged $\geq 18$ years in metropolitan areas-United States, 2015-2017. Morb. Mortal. Wkly. Rep. 2019, 68, 967. [CrossRef] [PubMed]

58. Centers for Disease Control and Prevention, U.S. Opioid Prescribing Rate Maps. 2020. Available online: https://www.cdc.gov/drugoverdose/maps/rxrate-maps.html (accessed on 1 May 2020).

59. National Institute on Drug Abuse (NIDA) Prescription Opioids and Heroin; NIDA: Rockville, MD, USA, 2015.

60. Lunn, D.; Thomas, A.; Best, N.; Spiegelhalter, D. WinBUGS-A Bayesian modelling framework: Concepts, structure, and extensibility. Stat. Comput. 2000, 10, 325-337. [CrossRef]

61. Brooks, S.; Gelman, A. General methods for monitoring convergence of iterative simulations. J. Comput. Graph. Stat. 1998, 7, 434-455.

62. Watanabe, S. A Widely Applicable Bayesian Information Criterion. J. Mach. Learn. Res. 2013, 14, 867-897.

63. Marotta, P.; Hunt, T.; Gilbert, L.; Wu, E.; Goddard-Eckrich, D.; El-Bassel, N. Assessing Spatial Relationships between Prescription Drugs, Race, and Overdose in New York State from 2013 to 2015. J. Psychoact. Drugs 2019, 51, 360-370. [CrossRef]

64. Kaiser Family Foundation. Opioid Overdose Deaths by Gender. Available online: https://www.kff.org/other/ state-indicator/opioid-overdose-deaths-by-gender/ (accessed on 5 June 2020).

65. Zoorob, M. Fentanyl shock: The changing geography of overdose in the United States. Int. J. Drug Policy 2019, 70, 40-46. [CrossRef] [PubMed]

66. Edwards, R. Commentary: US mortality, geography, and the anti-social determinants of health. Prev. Med. 2016, 89, 324-326. [CrossRef]

67. Haffajee, R.; Lin, L.; Bohnert, A.; Goldstick, J. Characteristics of US counties with high opioid overdose mortality and low capacity to deliver medications for opioid use disorder. JAMA Netw. Open 2019, 2, e196373. [CrossRef] [PubMed]

68. Monash University Business School. How Economic Conditions Impact on Opioid Deaths in Australia, Monash University. 2020. Available online: https://www2.monash.edu/impact/articles/health-economics/ how-economic-conditions-impact-on-opioid-deaths-in-australia/ (accessed on 5 July 2020).

69. Nagelhout, G.; Hummel, K.; de Goeij, M.; de Vries, H.; Kaner, E.; Lemmens, P. How economic recessions and unemployment affect illegal drug use: A systematic realist literature review. Int. J. Drug Policy 2017, 44, 69-83. [CrossRef]

70. Graham, C. Understanding the role of despair in America's opioid crisis. In Policy 2020 Brookings; Brookings Institute: Washington, DC, USA, 2020.

71. Treffers, S. The Role of Social Capital in Drug Use and Dependence in Four Canadian Provinces. Electronic Theses and Dissertations, University of Windsor. Available online: https://scholar.uwindsor.ca/ etd/5770 (accessed on 1 May 2020).

72. Mazumdar, S.; Mcrae, I.; Mofizul, M. How can geographical information systems and spatial analysis inform a response to prescription opioid misuse? A discussion in the context of existing literature. Curr. Drug Abus. Rev. 2015, 8, 104-110. [CrossRef]

73. Spooner, C.; Hetherington, K. Social Determinants of Drug Use; National Drug and Alcohol Research Centre: Sydney, Australia; University of New South Wales: Kensington, Australia, 2005.

74. Shiels, M.; De González, A.; Best, A.; Chen, Y.; Chernyavskiy, P.; Hartge, P.; Khan, S.; Pérez-Stable, E.; Rodriquez, E.; Spillane, S.; et al. Premature mortality from all causes and drug poisonings in the USA according to socioeconomic status and rurality: An analysis of death certificate data by County from 2000-15. Lancet Public Health 2019, 4, e97-e106. [CrossRef]

75. Ayilara, O.; Zhang, L.; Sajobi, T.; Sawatzky, R.; Bohm, E.; Lix, L. Impact of missing data on bias and precision when estimating change in patient-reported outcomes from a clinical registry. Health Qual. Life Outcomes 2019, 17, 106. [CrossRef] 
76. Belzak, L.; Halverson, J. The opioid crisis in Canada: A national perspective. Health Promot. Chronic Dis. Prev. Can. 2018, 38, 224-233. [CrossRef] [PubMed]

77. Pietsch, J.; Paulick, T.; Schulz, K.; Flössel, U.; Engel, A.; Schmitter, S.; Schmidt, U. Escalation of methamphetamine-related crime and fatalities in the Dresden region, Germany, between 2005 and 2011. Forensic Sci. Int. 2013, 233, 51-54. [CrossRef]

78. Dwyer-Lindgren, L.; Bertozzi-Villa, A.; Stubbs, R.; Morozoff, C.; Shirude, S.; Unützer, J.; Naghavi, M.; Mokdad, A.; Murray, C. Trends and patterns of geographic variation in mortality from substance use disorders and intentional injuries among US counties, 1980-2014. JAMA 2018, 319, 1013-1023. [CrossRef]

79. Finkelstein, A.; Gentzkow, M.; Williams, H. What Drives Prescription Opioid Abuse? Evidence from Migration. Stanford Institute for Economic Policy Research. Working Paper No. 18-028. 2018. Available online: https://siepr.stanford.edu/sites/default/files/publications/18-028.pdf (accessed on 11 May 2020).

80. Slavova, S.; O’Brien, D.; Creppage, K.; Dao, D.; Fondario, A.; Haile, E.; Hume, B.; Largo, T.; Nguyen, C.; Sabel, J.; et al. Drug overdose deaths: Let's get specific. Public Health Rep. 2015, 130, 339-342. [CrossRef]

81. Besag, J.; York, J.; Mollié, A. Bayesian image restoration, with two applications in spatial statistics. Ann. Inst. Stat. Math. 1991, 43, 1-20. [CrossRef]

82. Zhou, M.; Li, L.; Dunson, D.; Carin, L. Lognormal and gamma mixed negative binomial regression. In Proceedings of the International Conference on Machine Learning, Edinburgh, UK, 1-26 July 2012; Volume 2012, pp. 1343-1350.

83. Karlis, D.; Xekalaki, E. Mixed Poisson distributions. Int. Stat. Rev. 2005, 73, 35-58. [CrossRef]

84. Little, R.; Rubin, D. Statistical Analysis with Missing Data; John Wiley: Hoboken, NJ, USA, 2019.

Publisher's Note: MDPI stays neutral with regard to jurisdictional claims in published maps and institutional affiliations. 